\title{
Proxy measures of household food consumption for food security assessment and surveillance: comparison of the household dietary diversity and food consumption scores
}

\author{
Gina Kennedy ${ }^{1, *}$, Andrea Berardo², Cinzia Papavero², Peter Horjus², Terri Ballard', \\ MarieClaude Dop ${ }^{1}$, Jan Delbaere ${ }^{2}$ and Inge D Brouwer ${ }^{3}$ \\ 'Nutrition and Consumer Protection Division, Food and Agriculture Organization of the United Nations, \\ Viale delle Terme di Caracalla, 00153 Rome, Italy: ${ }^{2}$ Vulnerability Analysis and Mapping Branch (ODAV), \\ World Food Programme, Rome, Italy: ${ }^{3}$ Division of Human Nutrition, Wageningen University, \\ Wageningen, The Netherlands
}

Submitted 21 September 2009: Accepted 14 April 2010: First published online 6 July 2010

\begin{abstract}
Objective: To provide an overview of the household dietary diversity score and the food consumption score, two indicators used for food security assessment and surveillance, and compare their performance in food security assessments in three countries.

Design: Cross-sectional cluster sampling design using an interview-administered structured questionnaire on household food security, including household-level food group consumption measured over $1 \mathrm{~d}$ and $7 \mathrm{~d}$.

Setting: Survey data are from Burkina Faso, Lao People's Democratic Republic (Lao PDR) and northern Uganda.

Subjects: Households in Burkina Faso ( $n$ 3640), Lao PDR ( $n$ 3913) and northern Uganda ( $n$ 1956).

Results: Spearman's correlation coefficients between the scores were 0.73 in Burkina Faso, 0.65 in Lao PDR and 0.53 in northern Uganda. Prevalence-adjusted kappa coefficients showed substantial strength of agreement in two countries. The proportion of agreement between the two scores ranged from $85 \%$ in Lao PDR to $65 \%$ in northern Uganda. Dietary profiles based on food group consumption using score tertiles were comparable. Rankings of the most foodinsecure areas within a country corresponded well in northern Uganda and Burkina Faso but not in Lao PDR. Both indicators showed moderate correlations with other proxy measures of food security.

Conclusions: The comparative study highlights the similarities and differences between the food consumption and household dietary diversity scores. Similar classification of the most food-insecure areas within sub-national levels was obtained. The choice of indicator for food security assessment and surveillance will vary depending on user needs.
\end{abstract}

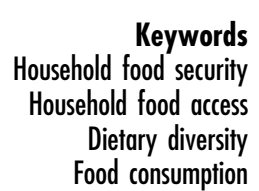

Many organizations involved in food security assessments use qualitative instead of quantitative measures of dietary intake. Quantitative dietary assessment techniques use data collected primarily at individual level to calculate dietary energy and nutrient intakes, which are then compared with nutrient requirements. Quantitative dietary survey methods are difficult to implement, particularly in developing countries, due to cost, logistics and other considerations such as respondent burden ${ }^{(1)}$. Qualitative measures of household food consumption, such as dietary diversity and food consumption scores, are attractive as the information required for their construction is less time-consuming and costly to collect than that for quantitative dietary intake methods.

Both the FAO and the World Food Programme (WFP) use information on dietary diversity as one element to inform food security analysis; however, the organizations use different data collection methods and analytical strategies $^{(2-4)}$. The FAO uses a $1 \mathrm{~d}$ household dietary diversity score (HDDS) based on guidelines produced by the Food and Nutrition Technical Assistance Project ${ }^{(5)}$ and the WFP uses a food consumption score (FCS). Both the HDDS and the FCS have been validated in different countries as proxy measures of household per capita 
Table 1 Main features of each method

\begin{tabular}{|c|c|c|}
\hline Characteristic & FCS & HDDS \\
\hline Recall method and time period & $\begin{array}{l}\text { List-based recall of } \mathrm{HH} \text { consumption } \\
\text { and frequency of consumption over } \\
\text { the past } 7 \mathrm{~d}\end{array}$ & $\begin{array}{l}\text { Qualitative 'free' recall of all food/drink } \\
\text { consumed by any HH membert during the } \\
\text { past } 24 \mathrm{~h}\end{array}$ \\
\hline $\begin{array}{l}\text { Number of food groups used to } \\
\text { create the score }\end{array}$ & 8 & 12 \\
\hline $\begin{array}{l}\text { Number of food groups in the } \\
\text { questionnaire }\end{array}$ & Varies by country context & 16 \\
\hline Weighting of food groups & $\begin{array}{l}\text { Each food group consumed receives a } \\
\text { weight from } 0.5 \text { to } 4\end{array}$ & $\begin{array}{l}\text { Each food group consumed has a value } \\
\text { (weight) of } 1\end{array}$ \\
\hline Typical cut-off points & $\begin{array}{l}\leq 21 \cdot 0=\text { poor } \\
21 \cdot 5-35 \cdot 0=\text { borderline } \\
>35 \cdot 0=\text { acceptable }\end{array}$ & $\begin{array}{l}\text { Population distribution of scores used to form } \\
\text { tertiles (or quartiles) for analysis of groups }\end{array}$ \\
\hline Out-of home-food consumption & Not counted in the FCS & Not counted in the HDDS \\
\hline
\end{tabular}

FCS, food consumption score; HDDS, household dietary diversity score; $\mathrm{HH}$, household. tIn this method food consumed by only one member of the $\mathrm{HH}$ and not the others is still recorded. For example, if a child was given a piece of fruit to eat as a snack this is recorded as 'yes' for fruit even if no other members of the $\mathrm{HH}$ ate fruit.

energy intake ${ }^{(6-9)}$. The tools are both used for monitoring and surveillance of household economic access to food ${ }^{(4)}$ and in both methods collected data can also be used to identify dietary patterns and consumption of specific foods. Information obtained from either measure is most useful for application within a given country or similar agro-ecological zone, rather than across countries and regions which have diverse dietary patterns.

FAO guidelines ${ }^{(2)}$ describe tools adapted for a decentralized* level utilizing simple data collection and analytical techniques requiring minimal statistical expertise. In addition to creation of a dietary diversity score for measuring population-level dietary diversity, the guidelines recommend creating dietary profiles and using the data to identify the proportion of households consuming food groups of special interest, such as dark green leafy vegetables or organ meat.

The FCS uses information on both dietary diversity and food frequency (number of days the food is consumed per week) and applies a weighting system ${ }^{(3)}$. Generally assessments are undertaken with national or regional WFP staff and analysis is performed by a trained staff member.

WFP and FAO have been called on to work together to support coherent action to address food insecurity ${ }^{(10)}$ and often work in the same countries and undertake joint food security assessments. There are also situations where FCS and HDDS could both be incorporated into decision making on food security; for example, both indicators could be available for use within the Integrated Food Security Phase Classification ${ }^{(11)}$. FAO and WFP have recognized the need to provide guidance on comparing results obtained from the two indicators and to work together to harmonize indicators currently used by each organization $^{(12)}$. The objective of the current study is to

* Tailored for use at various administrative levels including district and regional level, but also appropriate for use at national level. evaluate the similarities and differences between dietary patterns and food consumption classification obtained from the FCS and HDDS within three diverse settings.

\section{Methods}

Data sets from Burkina Faso, Lao People's Democratic Republic (Lao PDR) and northern Uganda were used in a comparative analysis of the household dietary diversity and food consumption tools. In each site, the survey included questions about household dietary diversity during the previous $24 \mathrm{~h}$ and past $7 \mathrm{~d}$. Tables 1 and 2 summarize the main methodological differences of the two measures in data collection, indicator construction and analytical approach. Table 2 looks more specifically at the food groups and weighting used to construct each score.

\section{Description of the bousebold dietary diversity metbodology}

The dietary diversity questionnaire in the HDD method elicits information on consumption of sixteen food groups over the reference period of the past $24 \mathrm{~h}$. The list of sixteen food groups is the same for any country/context. $\dagger$ The person primarily responsible for meal preparation for the household is asked to recall all meals, snacks and beverages consumed inside the home by any household member. The enumerator then checks with the respondent for any food groups not mentioned in the recall. To create the HDDS, the sixteen $\$$ food groups in the questionnaire are aggregated into twelve food groups. The HDDS is the sum of the number of the twelve food groups consumed (range 0-12; Table 2).

$\dagger$ In areas where red palm oil is consumed, the list of food groups is expanded to seventeen.

\$ Sixteen groups are collected to allow greater analytical flexibility. 
Table 2 Food groups used to construct the two scores

\begin{tabular}{|c|c|c|c|c|}
\hline \multicolumn{2}{|l|}{ FCS } & \multicolumn{3}{|c|}{ HDDS } \\
\hline Food group & Weight & Food group in questionnaire & Food group used to calculate HDDS & Weight \\
\hline \multirow[t]{2}{*}{ Cereals, tubers and root crops } & \multirow[t]{2}{*}{2} & Cereals & Cereals & 1 \\
\hline & & White roots and tubers & White roots and tubers & 1 \\
\hline \multirow[t]{3}{*}{ Meat and fish } & \multirow[t]{3}{*}{4} & $\begin{array}{l}\text { Organ meat } \\
\text { Flesh meat }\end{array}$ & Meat & 1 \\
\hline & & Fish & Fish & 1 \\
\hline & & Eggs & Eggs & 1 \\
\hline Milk & 4 & Milk and dairy & Milk and dairy & 1 \\
\hline Oil/fats & 0.5 & Oils and fat & Oils and fat & 1 \\
\hline Fruit & 1 & $\begin{array}{l}\text { VA-rich fruits } \\
\text { Other fruits }\end{array}$ & Fruits & 1 \\
\hline Vegetables & 1 & $\begin{array}{l}\text { VA-rich vegetables and tubers } \\
\text { Dark green leafy vegetables } \\
\text { Other vegetables }\end{array}$ & Vegetables & 1 \\
\hline Pulses & 3 & Pulses, legumes and nuts & Pulses, legumes and nuts & 1 \\
\hline Sugar & 0.5 & Sweets & Sweets & 1 \\
\hline Condiments (not counted in FCS) & 0 & Spices, condiments and beverages & Spices, condiments and beverages & 1 \\
\hline
\end{tabular}

FCS, food consumption score; HDDS, household dietary diversity score; VA, vitamin A.

Description of the food consumption methodology To construct the FCS, information on household-level food consumption is gathered from a country-specific list of food items and food groups. The respondent is asked about the household's frequency of consumption in number of days over the past week for each food group/ item. Food items are then grouped into eight specific food groups. The consumption frequencies (number of days of consumption over the previous $7 \mathrm{~d}$ ) of the eight groups are summed. Any frequency values over seven are capped at seven. This value obtained for each food group is multiplied by a food group weight. The sum of the weighted food group scores is the FCS.

\section{Description of the data sets}

In Lao PDR, WFP conducted a Comprehensive Food Security and Vulnerability Analysis survey. The sampling frame was based on data from the 2005 census. The sample included rural households from twenty-five villages in sixteen provinces, applying a two-stage cluster sample procedure. The total household sample size was 4000; out of these, 3926 households participated in the survey and 3913 households had complete data for both HDDS and FCS. The questionnaire included items on income, total expenditure, expenditure on food and asset ownership. To construct the FCS, food consumption information was collected on twenty-three food items. Respondents were asked whether anyone in the household had consumed the food item/food group in the past $7 \mathrm{~d}$ and if yes, the number of days the item/group was consumed. They were then asked whether anyone in the household had consumed the item/group in the previous $24 \mathrm{~h}$. The HDDS for Lao PDR is based on a sum of eleven instead of twelve food groups. The score does not include the food group spices, condiments and beverages.

In northern Uganda, WFP conducted an Emergency Food Security Assessment in 2007. The sample universe consisted of all villages in the resettled areas in Lira and all camps for internally displaced persons in Gulu, Pader, Kitgum, Apac \& Oyamin, and Amuria \& Katakwithe districts. Population figures in the camps were based on the WFP distribution figures and population figures for the resettlement area came from the Government of Uganda. A two-stage cluster sample procedure was applied. Camps or villages were selected with probability proportional to size, while households were randomly selected from a camp/village list. The total household sample size was 1980; out of these, 1958 households participated in the survey and 1956 households had complete data for both HDDS and FCS. Food consumption information was collected using a list of nineteen items. Respondents were asked the number of days each item/group was consumed inside the house during the past $7 \mathrm{~d}$ and the number of times anyone in the household consumed it in the previous $24 \mathrm{~h}$. The HDDS was based on a sum of eleven instead of twelve food groups. The score does not include the food group spices, condiments and beverages.

In Burkina Faso, WFP conducted a Nutritional Survey in 2007 in collaboration with UNICEF and with technical support of the Institut de Recherche pour le Développement. The survey was representative of five rural regions: Sahel, North, Central North, East and South West. Villages were selected by probability proportional to size and households within each village were selected using the random walk method. The sample included 3640 households, all with complete data for both HDDS and FCS. The HDDS is constructed using all twelve recommended food groups.

\section{Data analysis}

Data analysis was carried out using the SPSS for Windows statistical software package version $13 \cdot 0$ (SPSS Inc., Chicago, IL, USA). Statistical significance was assessed at $P<0 \cdot 05$. 
Table 3 Descriptive statistics for FCS and HDDS in Burkina Faso, Lao People's Democratic Republic (Lao PDR) and northern Uganda (N. Uganda)

\begin{tabular}{lccc}
\hline Indicator & $\begin{array}{c}\text { Burkina Faso } \\
(n \text { 3640) }\end{array}$ & $\begin{array}{c}\text { Lao PDR } \\
(n \text { 3913) }\end{array}$ & $\begin{array}{c}\text { N. Uganda } \\
(n \text { 1956) }\end{array}$ \\
\hline FCS & & & $36 \cdot 1$ \\
Mean & $45 \cdot 0$ & $51 \cdot 1$ & $12 \cdot 2$ \\
SD & $16 \cdot 4$ & $13 \cdot 9$ & $5-100$ \\
Range & $5 \cdot 5-112$ & $8-112$ & $3 \cdot 3$ \\
HDDS & $4 \cdot 6$ & $5 \cdot 2$ & $1 \cdot 4$ \\
Mean & $1 \cdot 3$ & $2 \cdot 1$ & $0-11$ \\
SD & $0-11$ & $1-11$ & $0 \cdot 53^{*}$ \\
Range & $0 \cdot 73^{*}$ & $0 \cdot 65^{*}$ & \\
Spearman correlation between & & & \\
FCS and HDDSt & & & \\
\hline
\end{tabular}

FCS, food consumption score; HDDS, household dietary diversity score.

${ }^{*}$ Correlation was statistically significant $(P<0.05)$.

tScatter plots of FCS by HDDS are provided as supplementary figures 1-3.

Descriptive statistics are reported taking into account survey design. Spearman's correlation was used to test the correlation between the two scores and between each score and other food security indicators. The kappa coefficient $(\boldsymbol{\kappa})$ was used to assess the proportion of agreement between the percentage of food groups consumed based on the recall periods and the percentage of 'habitual' consumption:

$$
\kappa=\left(P_{\mathrm{O}}-P_{\mathrm{C}}\right) /\left(1-P_{\mathrm{C}}\right),
$$

where $P_{\mathrm{O}}$ is the proportion of observed agreements and $P_{\mathrm{c}}$ is the proportion of agreement expected by chance ${ }^{(13)}$. The kappa coefficient is influenced by prevalence and becomes lower when frequency of the desired outcome is low or high. To account for this, both unadjusted and prevalence-adjusted kappa coefficients were calculated. The Landis and Koch definitions of fair, moderate and substantial strength of agreement were used ${ }^{(14)}$.

Theoretical probabilities of consumption of selected food groups on one out of seven days were calculated in order to compare these with reported consumption over the $1 \mathrm{~d}$ period. The theoretical probability of one-day consumption of a food group was calculated as:

$$
\frac{1}{7} \sum_{i=0}^{7} i \times p_{i},
$$

where $p_{i}$ is the percentage of households consuming the food group over $i$ days of the week. If the food group was not consumed at all over the week, its probability of being consumed in the past $24 \mathrm{~h}$ is $0 / 7$ or $0 \%$, whereas if it was consumed every day of the week, its probability is $7 / 7$ or $100 \%$; and so on. The probability of consumption in the past $24 \mathrm{~h}$ for each food group was then multiplied by the percentage of households reporting $i$ number of days of consumption. A $Z$ test for proportions was used to compare the percentage of households consuming the food groups over the $1 \mathrm{~d}$ recall with its theoretical probability of one-day consumption.

Cut-off points of the FCS and the HDDS were used to compare classification of food-insecure areas at sub-national levels. WFP has established cut-off points of FCS $\leq 21 \cdot 0$ to indicate poor food consumption and FCS $=21 \cdot 5-35 \cdot 0$ to indicate borderline food consumption ${ }^{(3)}$. The FAO guidelines $^{(2)}$ do not provide a standardized cut-off point for defining food-insecure households. In the current analysis a cut-off point for HDDS of $\leq 3$ food groups was compared with FCS $\leq 35 \cdot 0$ (poor and borderline food consumption).

\section{Results}

\section{Descriptive statistics and correlation between the two scores}

The mean FCS and HDDS for each country are presented in Table 3. Spearman's correlations between FCS and HDDS were significant in all three countries. The best correspondence to FCS $\leq 21 \cdot 0$ was HDDS between 2 and 3 food groups, while FCS $\leq 35 \cdot 0$ corresponded to HDDS slightly higher than 3 .

Unadjusted kappa coefficients showed a moderate strength of agreement in Burkina Faso and fair strength of agreement in Lao PDR and northern Uganda (Table 4). Over $80 \%$ of households were classified the same way in Burkina Faso and Lao PDR. There were fewer similar classifications in northern Uganda. Adjusting the kappa coefficients for prevalence improved the strength of agreement in Burkina and Lao PDR, but not in northern Uganda.

Figure 1 illustrates a comparison between the percentage of positive response over $1 \mathrm{~d}$ and the probability of obtaining the same percentages over a $7 \mathrm{~d}$ period using the theoretical probabilities described in the Methods section. Comparisons are made for those food groups which have the same definition for both indicators. There was a consistent tendency across all countries for a slightly higher percentage of households to report consuming the food groups over the past $24 \mathrm{~h}$ compared with their theoretical consumption probabilities of one out of seven days. These differences were significant for all food groups except for dairy in Lao PDR and northern Uganda and dairy, oil and pulses in Burkina Faso. 
Table 4 Kappa coefficients for HDDS and FCS in Burkina Faso, Lao People's Democratic Republic (Lao PDR) and northern Uganda (N. Uganda)

\begin{tabular}{llccccc}
\hline & & \multicolumn{2}{c}{ Kappa } & & \multicolumn{2}{c}{ Strength of agreement } \\
\cline { 3 - 4 } & & Unadjusted & Prevalence adjusted & $\begin{array}{c}\text { Proportion of } \\
\text { agreement (\%) }\end{array}$ & Unadjusted score & Adjusted score \\
\hline Burkina Faso & HDDS $\leq 3$ and FCS $\leq 35$ & 0.57 & 0.65 & 82 & Moderate & Substantial \\
Lao PDR & HDDS $\leq 2$ and FCS $\leq 35$ & 0.34 & 0.72 & 85 & Fair & Substantial \\
& HDDS $\leq 3$ and FCS $\leq 35$ & 0.40 & 0.61 & 80 & Fair & Substantial \\
N. Uganda & HDDS $\leq 2$ and FCS $\leq 35$ & 0.31 & 0.33 & 65 & Fair & Fair \\
& HDDS $\leq 3$ and FCS $\leq 35$ & 0.33 & 0.35 & 66 & Fair & Fair \\
\hline
\end{tabular}

HDDS, household dietary diversity score; FCS, food consumption score.

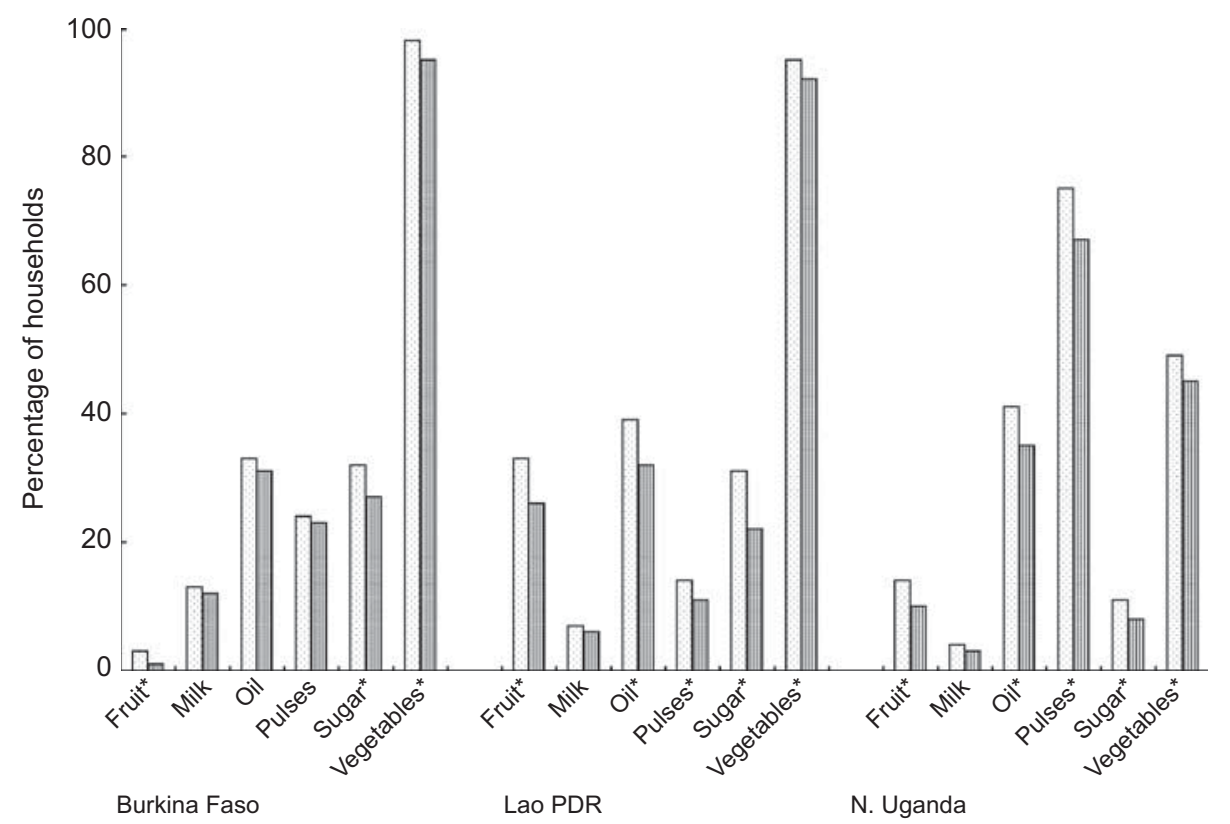

Fig. 1 Comparison of $1 \mathrm{~d}$ recall ( $)$ and theoretical probability of consuming the food group on one out of seven days (III) in Burkina Faso, Lao People's Democratic Republic (Lao PDR) and northern Uganda (N. Uganda). *Significant difference between percentages $(P<0.05)$

\section{Comparing prevalence of food insecurity at sub-national level}

For programmatic purposes it is important to identify the most disadvantaged areas within a country. In the current analysis we used the FCS definition of 'poor and borderline food consumption' (FCS $\leq 35 \cdot 0$ ) compared with HDDS $\leq 3$. The percentage of households with low FCS and low HDDS along with the respective rank by each score are shown in Table 5. Applying a 'prevalence threshold' (30\% or more of households below the cut-off points in this example) to distinguish food-secure and food-insecure strata resulted in similar classification of three out of five regions in Burkina Faso, ten out of sixteen provinces in Lao PDR and eight out of nine strata in northern Uganda. In Burkina Faso, there was correspondence of rank for three out of five subnational strata. The rankings were the same for the three most food-insecure regions. In northern Uganda, there was correspondence of rank in four out of nine strata. Both scores ranked Apac \& Oyam and Pader transit camps as the first and second most food-insecure areas. In Lao PDR, rankings for HDDS and FCS corresponded in Bokeo, ranked most food insecure, and in Vientiane and Champassak, ranked most food secure. We made no attempt to compare sub-national strata across counties because scores are influenced by differences in dietary patterns.

\section{Correlation of the two scores with other indicators of food security}

The FCS and HDDS demonstrated similar strength of correlation with other food security indicators (Table 6). In Burkina Faso and Lao PDR there were no striking differences in the magnitude or significance of the correlation coefficients. In northern Uganda, the FCS presented higher correlation coefficients with every tested indicator, with the exception of percentage of expenditure on food.

\section{Analysis of dietary patterns}

The dietary profiles of the lowest and highest tertiles for HDDS and FCS are compared in Table 7. The food groups 
Table 5 Ranking of FCS and HDDS by geographical strata in Burkina Faso, Lao People's Democratic Republic (Lao PDR) and northern Uganda (N. Uganda)

\begin{tabular}{|c|c|c|c|c|}
\hline & \multicolumn{2}{|c|}{ Rankingt of $\% \mathrm{HH}$ below cut-off point } & \multicolumn{2}{|c|}{ Percentage of $\mathrm{HH}$ below cut-off point } \\
\hline & Using FCS & Using HDDS & $\mathrm{FCS} \leq 35$ & $\mathrm{HHDS} \leq 3$ \\
\hline \multicolumn{5}{|l|}{ Burkina Faso } \\
\hline \multicolumn{5}{|l|}{ Region } \\
\hline Centre North & 2 & 2 & 38 & 26 \\
\hline East & 5 & 4 & 22 & 14 \\
\hline North & 3 & 3 & 30 & 19 \\
\hline Sahel & 4 & 5 & 25 & 15 \\
\hline South West & 1 & 1 & 51 & 34 \\
\hline \multicolumn{5}{|l|}{ Lao PDR } \\
\hline \multicolumn{5}{|l|}{ Provinces } \\
\hline Attapeu & 12 & 4 & 9 & 34 \\
\hline Bokeo & 1 & 1 & 42 & 61 \\
\hline Bolikhamxay & 13 & 14 & 4 & 9 \\
\hline Champassak & 16 & 16 & 2 & 3 \\
\hline Huapanh & 5 & 8 & 21 & 25 \\
\hline Khammouane & 10 & 2 & 10 & 49 \\
\hline Luang Namtha & 9 & 11 & 16 & 14 \\
\hline Luang Prabang & 8 & 5 & 17 & 32 \\
\hline Oudomxay & 6 & 3 & 19 & 41 \\
\hline Phongsali & 7 & 10 & 19 & 19 \\
\hline Saravane & 2 & 13 & 30 & 13 \\
\hline Savannakhet & 14 & 12 & 4 & 14 \\
\hline Sekong & 4 & 6 & 25 & 31 \\
\hline Vientiane & 15 & 15 & 4 & 9 \\
\hline Xayaboury & 11 & 7 & 10 & 28 \\
\hline Xieng Khoang & 3 & 9 & 26 & 21 \\
\hline \multicolumn{5}{|l|}{ N. Uganda } \\
\hline \multicolumn{5}{|l|}{ Strata } \\
\hline Gulu Mother Camp & 5 & 3 & 45 & 81 \\
\hline Gulu Transit Camp & 3 & 6 & 51 & 63 \\
\hline Kitgum Mother Camp & 4 & 4 & 50 & 71 \\
\hline Kitgum Transit Camp & 7 & 5 & 43 & 68 \\
\hline Pader Mother Camp & 8 & 7 & 38 & 61 \\
\hline Pader Transit Camp & 2 & 2 & 76 & 82 \\
\hline Apac \& Oyam Mother Camps & 1 & 1 & 82 & 84 \\
\hline Amuria \& Katakwi Mother Camps & 9 & 9 & 28 & 40 \\
\hline Lira Resettlement & 6 & 8 & 46 & 49 \\
\hline
\end{tabular}

FCS, food consumption score; HDDS, household dietary diversity score; $\mathrm{HH}$, household.

tRank of 1 is most food insecure.

listed for the HDDS column represent those food groups consumed by $50 \%$ or more of the households in the given tertile. The food groups listed for FCS represent food groups consumed on $\geq 3 \mathrm{~d}$ and $\geq 4 \mathrm{~d}$ of the previous $7 \mathrm{~d}$ by $50 \%$ or more of the households in the given tertile.

The dietary profiles for the lowest tertiles of HDDS and FCS provide nearly the same picture for all three countries. When looking at food groups consumed by households in the highest tertiles, the HDD method appears to capture more detail. Comparing food groups consumed three or more rather than four or more times per week corresponded better with HDD profiles.

\section{Discussion}

Correlation coefficients of the two scores were significant in all countries. Adjusted kappa coefficients showed substantial agreement in overall classification for two out of three countries. When looking at sub-national rankings, there was agreement by rank of the most food-insecure area in all three countries. Rankings of the more foodsecure areas were more discrepant, particularly in Lao PDR. Dietary profiles for the lowest score tertiles were nearly identical, with greater differences in food group consumption across the two measures for the highest tertiles. Both scores performed similarly when correlated with other indicators of food security available in each data set. One limitation of the present study is the score cut-off points used. Application of a universal cut-off point across countries may carry different interpretations, particularly at upper ends of the scores, due to regional variations in dietary patterns and food systems ${ }^{(15)}$.

The remainder of the discussion aims to provide a description of how the main differences between the two methods affect the comparability of the two scores. The main methodological differences include: (i) the number and definitions of food groups used to construct the score; (ii) the length of reference period used in the recall; (iii) the application of weights to food groups; and 
Table 6 Correlation of FCS and HDDS with other indicators of food security in Burkina Faso, Lao People's Democratic Republic (Lao PDR) and northern Uganda (N. Uganda)

\begin{tabular}{|c|c|c|c|}
\hline Country & Food security indicator & Correlation with FCS & Correlation with HDDS \\
\hline \multirow[t]{5}{*}{ Burkina Faso } & Number of meals the day before & & \\
\hline & Children aged $0-5$ years & $0 \cdot 27^{*}$ & $0 \cdot 22^{*}$ \\
\hline & Children aged $6-14$ years & $0 \cdot 30^{*}$ & $0 \cdot 28^{\star}$ \\
\hline & Females aged 15 years or older & $0 \cdot 32^{*}$ & $0 \cdot 33^{*}$ \\
\hline & Males aged 15 years or older & $0 \cdot 29^{*}$ & $0 \cdot 30^{*}$ \\
\hline \multirow[t]{6}{*}{ Lao PDR } & $\mathrm{HH}$ total expenditure & $0 \cdot 30^{*}$ & $0 \cdot 30^{*}$ \\
\hline & Total food expenditure & $0 \cdot 23^{*}$ & $0 \cdot 24^{\star}$ \\
\hline & Per capita food expenditure & $0 \cdot 22^{*}$ & $0 \cdot 22^{*}$ \\
\hline & Per capita non-food expenditure & $0 \cdot 31^{*}$ & $0 \cdot 28^{\star}$ \\
\hline & Percentage food expenditure & $-0 \cdot 04^{\star}$ & -0.01 \\
\hline & Asset index & $0 \cdot 32^{*}$ & $0.33^{*}$ \\
\hline \multirow[t]{11}{*}{ N. Uganda } & $\mathrm{HH}$ total expenditure & $0 \cdot 27^{*}$ & $0 \cdot 17^{*}$ \\
\hline & Total food expenditure & $0 \cdot 17^{\star}$ & $0.08^{*}$ \\
\hline & Total non-food expenditure & $0 \cdot 30^{*}$ & $0 \cdot 22^{\star}$ \\
\hline & Per capita total expenditure & $0 \cdot 24^{*}$ & $0 \cdot 16^{\star}$ \\
\hline & Per capita food expenditure & $0 \cdot 14^{*}$ & $0 \cdot 06^{*}$ \\
\hline & Per capita non-food expenditure & $0 \cdot 29^{*}$ & $0 \cdot 22^{*}$ \\
\hline & Percentage food expenditure & $-0 \cdot 05^{\star}$ & $-0 \cdot 11^{\star}$ \\
\hline & Number of meals the day before & & \\
\hline & Adults aged 13 years or older & $0 \cdot 32^{*}$ & $0 \cdot 22^{*}$ \\
\hline & Children aged $\leq 6$ years & $0 \cdot 23^{*}$ & $0 \cdot 11^{*}$ \\
\hline & Children aged $7-12$ years & $0 \cdot 24^{*}$ & $0 \cdot 16^{*}$ \\
\hline
\end{tabular}

FCS, food consumption score; HDDS, household dietary diversity score; $\mathrm{HH}$, household.

${ }^{*}$ Correlation was statistically significant $(P<0 \cdot 05)$.

Table 7 Dietary profiles using HDDS and FCS tertiles

\begin{tabular}{|c|c|c|c|c|c|c|}
\hline \multirow[b]{2}{*}{ Country } & \multicolumn{3}{|c|}{ Lowest tertile } & \multicolumn{3}{|c|}{ Highest tertile } \\
\hline & HDDS & $\mathrm{FCS} \geq 3 \mathrm{~d}$ & $\mathrm{FCS} \geq 4 \mathrm{~d}$ & HDDS & $\mathrm{FCS} \geq 3 \mathrm{~d}$ & $\mathrm{FCS} \geq 4 \mathrm{~d}$ \\
\hline Burkina & Cereals & Cerealst & Cerealst & Cereals & Cerealst & Cerealst \\
\hline Faso & $\begin{array}{l}\text { Vegetables } \\
\text { Condiments (not a } \\
\text { group in FCS) }\end{array}$ & $\begin{array}{l}\text { Vegetables } \\
\text { Fruit }\end{array}$ & Vegetables & $\begin{array}{l}\text { Vegetables } \\
\text { Fish } \\
\text { Sugar } \\
\text { Oil } \\
\text { Condiments (not a } \\
\quad \text { group in FCS) }\end{array}$ & $\begin{array}{l}\text { Vegetables } \\
\text { Meat/fish/eggs } \\
\text { Fruit } \\
\text { Sugar } \\
\text { Oil }\end{array}$ & $\begin{array}{l}\text { Vegetables } \\
\text { Meat/fish/eggs } \\
\text { Fruit }\end{array}$ \\
\hline Lao PDR & $\begin{array}{l}\text { Cereals } \\
\text { Vegetables }\end{array}$ & $\begin{array}{l}\text { Cerealst } \\
\text { Vegetables } \\
\text { Meat }\end{array}$ & $\begin{array}{l}\text { Cerealst } \\
\text { Vegetables }\end{array}$ & $\begin{array}{l}\text { Cereals } \\
\text { Tubers } \\
\text { Vegetables } \\
\text { Meat } \\
\text { Fish } \\
\text { Eggs } \\
\text { Fruit } \\
\text { Oil } \\
\text { Sugar }\end{array}$ & $\begin{array}{l}\text { Cerealst } \\
\text { Vegetables } \\
\text { Meat/fish/eggs } \\
\text { Fruit } \\
\text { Oil } \\
\text { Sugar }\end{array}$ & $\begin{array}{l}\text { Cerealst } \\
\text { Vegetables } \\
\text { Meat/fish/eggs }\end{array}$ \\
\hline N. Uganda & $\begin{array}{l}\text { Cereals } \\
\text { Pulses }\end{array}$ & $\begin{array}{l}\text { Cerealst } \\
\text { Vegetables }\end{array}$ & Cerealst & $\begin{array}{l}\text { Cereals } \\
\text { Pulses } \\
\text { Tubers } \\
\text { Vegetables } \\
\text { Oil }\end{array}$ & $\begin{array}{l}\text { Cerealst } \\
\text { Pulses } \\
\text { Vegetables } \\
\text { Oil }\end{array}$ & $\begin{array}{l}\text { Cerealst } \\
\text { Pulses }\end{array}$ \\
\hline
\end{tabular}

HDDS, household dietary diversity score; FCS, food consumption score; Lao PDR, Lao People's Democratic Republic; N. Uganda, northern Uganda. tThis food group includes cereals, tubers and root crops.

(iv) the construction of a score combining frequency and dietary diversity.

\section{Number and definition of food groups}

When comparing results of dietary patterns by tertiles, the HDD method captured more detail in the highest tertile, while the lowest tertile for both methods reflected the same diet. The number and definition of food groups is mainly responsible for the variation in detail seen at the higher levels of each score. The rationale in the HDD method for including a more disaggregated list of food groups is to allow more versatility with analysis. For example, disaggregation of animal source foods into four groups (meat, fish, eggs and dairy) allows for detection of differences in consumption of these foods across groups with different characteristics or over time. 
The province of Saravane in Lao PDR provides a good example of how the definition of food groups affected the scores. The percentage of households falling below the defined cut-off point was $30 \%$ for FCS and $13 \%$ for HDDS. Saravane was ranked as the second most foodinsecure area by FCS, but as one of the most food-secure areas (thirteenth out of sixteen) by HDDS. Eighty-nine per cent, $63 \%$ and $41 \%$ of households reported consuming meat, fish and eggs over the past $24 \mathrm{~h}$. For calculation of FCS, these food groups are aggregated into one group. Fifty-two per cent of households consumed meat/fish/ eggs all seven days, the equivalent of 28 points for FCS. Consumption of the meat/fish/egg food group for the remaining $48 \%$ was spread evenly across zero to six days. There was also a tendency in this province for foods reported consumed only two to three times per week, to have been reported consumed in the previous $24 \mathrm{~h}$.

\section{Length of reference period}

The analysis indicated that the $24 \mathrm{~h}$ household recall of individual food groups was always slightly higher than what would have been hypothetically captured for any one day out of a recall period of $7 \mathrm{~d}$. For example, in the $24 \mathrm{~h}$ recall, oil was reported as consumed by $33 \%, 39 \%$ and $41 \%$ of households in Burkina Faso, Lao PDR and northern Uganda, while the theoretical probability of consuming oil on any given day was $31 \%, 32 \%$ and $35 \%$, respectively. Most of the differences were small but statistically significant, and could be explained by a level of over-reporting for $1 \mathrm{~d}$, under-reporting over $7 \mathrm{~d}$ or some combination of both errors.

Previous research suggests that the most likely explanation is under-reporting during the longer recall period rather than over-reporting during the $1 \mathrm{~d}$ recall. Recall error increases the longer back into the past respondents are asked to remember and this memory error leads to under-reporting of consumption ${ }^{(16)}$. Savy et al. found that there was a greater recall error with $2 \mathrm{~d}$ and $3 \mathrm{~d}$ recalls compared with $1 \mathrm{~d}$ recalls ${ }^{(17)}$.

\section{Weighting of food groups}

The HDDS weights all food groups equally as if each food group were assigned a weight of 1 , whereas the FCS applies a weighting system to the different food groups. Weighting had an impact on the comparability of the two scores in the present analysis. Provincial-level data from Lao PDR were analysed in more depth to investigate the greater divergence. The diet in Lao PDR is dominated by cereals, vegetables and fish. FCS weights assigned to cereals, vegetables and fish are 2, 1 and 4, respectively, while in the HDDS each of these food groups has a weight of 1 . If the three food groups were consumed by the household over the previous day, the HDDS would be 3 while the FCS would be 7 . The magnitude of the difference between the two scores is compounded by the number of days in the week that the higher weighted food groups are consumed. These differences may become particularly evident in more food-secure areas where availability of food groups assigned higher weights by FCS such as meat, fish and milk is greater.

Research on the FCS has shown the weights used do not improve the accuracy of the score over an unweighted score in terms of correlation with energy intake ${ }^{(8)}$. Rose et al. found that when comparing various types of food consumption scores, the use of food group weights based on formulas derived in a locally specific context provided the strongest correlation with a proxy measure of household dietary energy availability ${ }^{(9)}$. While locally designed weighting systems may produce the strongest correlations, the data needed to construct them are often not available. Rose et al. conclude that differences in performance of weighted compared with unweighted scores did not merit replacing an existing data collection system, but could be considered in new systems. If performance of the indicator is improved, then weights may be warranted in both the FCS and HDDS. Further validation of the appropriate weights to use is needed. However, assigning locally derived weights for use in specific locations would reduce the measure's value as a standardized indicator for multi-country use.

\section{Combining dietary diversity with frequency of consumption}

Traditional food frequency methodology uses a combination of diversity and frequency, but generally to assess dietary patterns over a much longer time frame of months to a year. The International Food Policy Research Institute (IFPRI) concluded that indicators based on a recall period of $7 \mathrm{~d}$ combining frequency (number of times consumed per week) and diversity were preferable to scores using only diversity ${ }^{(8)}$. In two out of three countries in the IFPRI study, the FCS, which takes the frequency of consumption into account, correlated better with household energy intake than simpler measures using only dietary diversity. The merit of a score based on a $1 \mathrm{~d}$ recall period combining frequency (number of times per day) of consumption with diversity has not been the subject of much research in developing countries, but the added accuracy achieved with scores that combine frequency and diversity should be weighed against the additional time and effort required for survey training, data collection, respondent fatigue and data analysis.

\section{Conclusions}

Both the HDDS and the FCS are used as proxy indicators of household access to food; however, the indicators are not interchangeable and a decision as to which one to collect should be made before undertaking any data collection. The current analysis showed that the choice of number of food groups and the use of weighting have an impact on the comparability of the indicators. 
Harmonization of certain aspects of data collection and analysis, such as the number and types of food groups used to create the indicator, could be one step towards improving comparability. More work is needed on both methods to identify the most appropriate cut-off points for defining food-insecure populations. The choice between collecting information for HDD or FCS depends on the time and resources available for data collection and the needs of the user. The HDD tool provides a useful snapshot of the situation at population level and is an attractive choice for ongoing tracking of programmes and in situations where time and resources for data collection and analysis are limited. The FCS, due to the combination of a longer reference period and incorporation of consumption frequency, requires slightly more data collection time but provides a more complete picture of consumption, and may be chosen by practitioners when more detail is needed, such as during in-depth food security assessments. Emphasis should be placed on consistent use of the chosen indicator to allow tracking of trends over time or comparisons across locations.

\section{Acknowledgements}

Sources of funding: This work was supported in part under the WFP Strengthening Emergency Needs Assessment Implementation Plan (SENAIP), which obtained financial support from ECHO (European Commission Humanitarian Aid), the UK Department for International Development (DFID), the German Agency for Technical Cooperation (GTZ), the Canadian International Development Agency (CIDA), the Citigroup Foundation, and the Danish and French governments. Conflict of interest: None. Author contributions: A.B., J.D., P.H. and G.K., study concept; T.B., M.C.D., G.K., A.B., I.D.B. and J.D., study design; G.K., A.B., C.P. and P.H., data analysis; G.K. and A.B., preparation of the manuscript; C.P., P.H., T.B., M.C.D., J.D. and I.D.B., interpretation and technical revision. All authors have seen and approved the contents of the manuscript.

\section{References}

1. Food and Agriculture Organization of the United Nations (2003) Measurement and Assessment of Food Deprivation and Undernutrition. Proceedings from the International Scientific Symposium on Measurement and Assessment of Food Deprivation and Undernutrition, 26-28 June 2002, Rome, Italy. Rome: FAO.

2. Food and Agriculture Organization of the United Nations (2004) Guidelines for Measuring Household and Individual
Dietary Diversity, Version 4. http://www.foodsec.org/tr/ nut/guidelines.pdf (accessed June 2009).

3. World Food Programme, Vulnerability Analysis and Mapping Branch (2007) Technical Guidance Sheet. Food Consumption Analysis. Calculation and Use of the Food Consumption Score in Food Consumption and Food Security Analysis. http://www.wfp.org/food-security/references (accessed June 2009).

4. World Food Programme (2009) Comprehensive Food Security and Vulnerability Analysis Guidelines. http://documents.wfp. org/stellent/groups/public/documents/manual_guide_proced/ wfp203199.pdf (accessed June 2009).

5. Swindale A \& Bilinsky P (2006) Housebold Dietary Diversity Score (HDDS) for Measurement of Household Food Access: Indicator Guide (version 2). Washington, DC: Food and Nutrition Technical Assistance Project, Academy for Educational Development.

6. Hoddinott J \& Yohannes Y (2002) Dietary Diversity as a Food Security Indicator. Washington, DC: Food and Nutrition Technical Assistance Project, Academy for Educational Development.

7. International Food Policy Research Institute (2006) Review and Validation of Dietary Diversity, Food Frequency and Other Proxy Indicators of Household Food Security. Paper prepared for WFP/VAM as part of Strengthening Emergency Needs Assessment Capacity (SENAC). Rome: World Food Programme.

8. Wiesmann D, Bassett L, Benson T et al. (2009) Validation of the World Food Programme's Food Consumption Score and Alternative Indicators of Household Food Security. IFPRI Discussion Paper no. 00870. Washington, DC: International Food Policy Research Institute.

9. Rose D, Chotard S, Oliveira L et al. (2008) Comparative evaluation of dietary indicators used in food consumption assessments of at-risk populations. Food Nutr Bull 29, 113-122.

10. World Food Programme (2008) Progress report on the Implementation of the World Food Summit Plan of Action. ftp://ftp.fao.org/docrep/fao/meeting/013/ai753e.pdf (accessed June 2009).

11. IPC Global Partners (2008) IPC Technical Manual version 1.1. http://www.ipcinfo.org/tech.php (accessed June 2009).

12. World Food Programme, Vulnerability Analysis and Mapping Branch \& Food and Agriculture Organization of the United Nations (2008) Interagency workshop report. Measures of food consumption - harmonizing methodologies. http://documents.wfp.org/stellent/groups/public/ documents/ena/wfp196629.pdf (accessed June 2009).

13. Sim J \& Wright C (2005) The kappa statistic in reliability studies: use, interpretation and sample size requirements. Phys Ther 85, 257-268.

14. Landis RJ \& Koch GG (1977) The measurement of observer agreement for categorical data. Biometrics 33, 159-174.

15. Ruel MT (2003) Operationalizing dietary diversity: a review of measurement issues and research priorities. J Nutr 133, 11 Suppl. 2, 3911S-3926S.

16. Jelliffe DB \& Jelliffe EFP (1989) Community Nutritional Assessment. New York: Oxford University Press.

17. Savy M, Martin-Prevel Y, Traissac P et al. (2007) Measuring dietary diversity in rural Burkina Faso: comparison of a 1-day and a 3-day dietary recall. Public Health Nutr 10, $71-78$. 